\title{
Obtención de los principales parámetros del agua residual urbana empleados en los modelos matemáticos de fangos activados a partir de una caracterización analítica simple
}

\section{Obtaining of the principals parameters from urban wastewater used in the mathematical activated sludge models through basic characterization}

\author{
J.E. Sánchez-Ramírez ${ }^{1 *}$, Josep Ribes ${ }^{3}$, José Ferrer ${ }^{4}, M^{a}$ Francisca García-Usach ${ }^{2}$
}

\begin{abstract}
Resumen
El tratamiento de las aguas residuales se ha realizado en España mediante procesos biológicos como el comúnmente utilizado de fangos activados. Estos procesos han sido descritos mediante modelos matemáticos que describen la eliminación de los contaminantes presentes en el agua (materia orgánica, nitrógeno y fósforo). La utilización de estos modelos requiere de una caracterización detallada de los contaminantes presentes en el agua residual urbana (ARU). La caracterización de un ARU es clave para el uso de estos modelos de simulación, tanto en el diseño como en la simulación de las Estaciones Depuradoras de Aguas Residuales (EDAR). Este trabajo ha utilizado y considerado los parámetros propuestos en el modelo de fangos activados BNRM1, siendo este modelo una ampliación del modelo ASM2d propuesto por la International Water Association (IWA). El objetivo principal de este trabajo es la realización de un estudio estadístico que permita obtener relaciones entre los datos analíticos utilizados para la caracterización del ARU según los modelos matemáticos de fangos activados. La obtención de todos los componentes del modelo matemático a partir de poca información teniendo en cuenta que no siempre se dispone de todos los datos necesarios para caracterizar el agua, exige la realización de suposiciones y consideraciones basadas en: la experiencia del diseñador, datos encontrados en diferentes plantas y datos bibliográficos obtenidos a partir de ARU analizadas en diferentes lugares. El presente estudio se realizó a partir de datos obtenidos en caracterizaciones de ARU de diferentes EDAR de la Comunidad Valenciana y la región de Murcia (Valencia, España).
\end{abstract}

Palabras clave: Aguas residuales; fangos activados; modelos matemáticos; caracterización

\begin{abstract}
The wastewater treatment in Spain has been through biological processes such as the commonly used in activated sludge. These processes have been described using mathematical models that describe the elimination of contaminants in the wastewater (organic matter, $\mathrm{N}$ and $\mathrm{P}$ ). The use of these models requires a detailed characterization of the contaminants in the urban wastewater. The characterization of this wastewater is key to the use of these simulation models, both in design and simulation of the wastewater treatments plants (WWTP). This work has used and considered them parameters proposed in the model of sludge activated BNRM1 (Biological Nutrient Removal), being this model an enlargement of the model ASM2d proposed by the International Water Association (IWA). The main objective of this study is a statistical study that allows obtaining relations between the analytical data used for the characterization of the wastewater according to mathematical models of activated sludge. The obtaining of all components of the model mathematical starting from little information having in has that not always is has of all them data necessary to characterize the water, requires the realization of assumptions and considerations based in; the experience of the designer, data found in different plants and data bibliographic obtained from urban wastewater analyzed in different places. The present study is performed starting from data obtained in characterizations of urban wastewater of different WWTP of the Valencia community and Murcia region (Valencia, Spain).
\end{abstract}


11PhD Ingeniería Química ambiental y de procesos. Dpto I+D Depuración de Aguas del Mediterráneo. Email: Javier.sanchez@dam-aguas.es
2PhD Ing. Hidráulica y Medio Ambiente. Email: Magarus@ gmail.com
${ }^{3} \mathrm{PhD}$ profesor Dpto. Ingeniería Química. U. de Valencia (España). Av de la Universitat, Burjassot. Email: Josep.ribes @uv.es
${ }^{4} \mathrm{PhD}$ Profesor Escuela de Caminos. U. Politécnica de Valencia (España). Camí de Vera. Email: jferrer@hma.upv.es

Keywords: wastewater; activated sludge; Mathematical models; Characterization

\section{Introducción}

Actualmente, el crecimiento de los núcleos urbanos ha puesto al descubierto la necesidad de desarrollar e implementar tecnologías con el fin de compensar los graves problemas de contaminación que se producen especialmente con el aumento de las aguas residuales urbanas. Los residuos líquidos llamados aguas residuales provienen de una mezcla de líquidos urbanos, industriales y pluviales. Un ARU puede definirse como un "residuo líquido recogido mediante la red de alcantarillado para su posterior envío a una planta de tratamiento" (Mujeriego et al., 1990). El tipo y la cantidad de ARU influente a una estación depuradora reflejan la naturaleza de la misma, el uso que se le ha dado y las condiciones del medio de conducción. El factor que más influye sobre el proceso de depuración de aguas residuales es sin duda su composición. Según su origen las aguas residuales se clasifican en: urbanas o domésticas, industriales, agropecuarias, pluviales y de origen incontrolado.

En el presente trabajo al hablar de aguas residuales nos referiremos a aguas de origen doméstico o urbano con alguna posible aportación de pluviales y de origen incontrolado. Las aguas residuales de origen doméstico presentan una composición muy variada debido a la diversidad de factores y la naturaleza de la población servida, la mayor fuente de contaminación que fluye por los sistemas recolectores tiene su origen en heces humanas y animales (excrementos y orina).

La mayor parte de los compuestos que se encuentran en el ARU se encuentran en forma particulada y soluble, el material particulado contiene aproximadamente un $70 \%$ de sustancias orgánicas (proteínas, grasas y carbohidratos) y el 30\% restante material insoluble (sustancias inorgánicas). Las aguas residuales a su vez contienen una gran variedad de microorganismos: virus, bacterias, hongos, protozoos y nematodos donde se estima que hay alrededor de 5 millones de especies en el "medio ambiente", a partir del cual, sólo el 5\% ha sido catalogada. Los microorganismos como parte importante de los ecosistemas transforman los compuestos orgánicos presentes en los ambientes acuáticos contribuyendo a la depuración de contaminantes.

La importancia de caracterizar las ARU es sin duda un factor fundamental en el desarrollo de nuevos procesos (Ekama et al., 1986) que garanticen una determinada calidad del afluente. Del mismo modo una caracterización adecuada del ARU utilizando los componentes de acuerdo a los modelos existentes es indispensable para el buen funcionamiento de los modelos y los procesos de fangos activados (Janssen ,1994).

La caracterización de un ARU es clave para el uso de modelos tanto en el diseño como en la simulación de plantas de tratamiento de aguas residuales EDAR. Cuando se pretende diseñar y modelar un proceso, la disponibilidad de información muchas veces insuficiente sobre las características del ARU hace imposible la obtención analítica de todos los componentes considerados en el modelo. La mayoría de análisis realizados a las ARU se presentan con muy pocos datos lo cual impide la correcta caracterización de las misma. La obtención de todos los componentes a partir de pocos datos exige la realización de suposiciones y consideraciones basadas en la experiencia o en datos encontrados en la bibliografía.

El presente trabajo muestra los resultados obtenidos en el estudio estadístico de los datos experimentales obtenidos en caracterizaciones realizadas en ARU, con el fin de proponer relaciones matemáticas entre los distintos datos experimentales y componentes incluidos en los modelos para fangos activados. Las relaciones obtenidas servirán para completar los datos experimentales faltantes en la caracterización de un ARU, así como calcular todos los componentes del ARU según el modelo utilizado de una manera más científica y sistemática. 


\section{Materiales y métodos}

\subsection{Fraccionamiento de la DQO}

La cantidad de sustrato presente en el agua influente se expresa comúnmente en términos de demanda química de oxigeno (DQO) siendo está una medida indirecta de la cantidad de materia orgánica (MO) presente en las aguas residuales, la DQO es la cantidad de oxígeno necesaria para oxidar químicamente la materia orgánica presente en una muestra líquida. El material carbonoso MO presente en las ARU se encuentra dividido en dos fracciones: biodegradable y no biodegradable que a su vez se dividen en soluble (S) y particulado (X) (Ekama y Marais, 1979). La Figura 1 muestra todas las fracciones en las que se descompone la DQO.

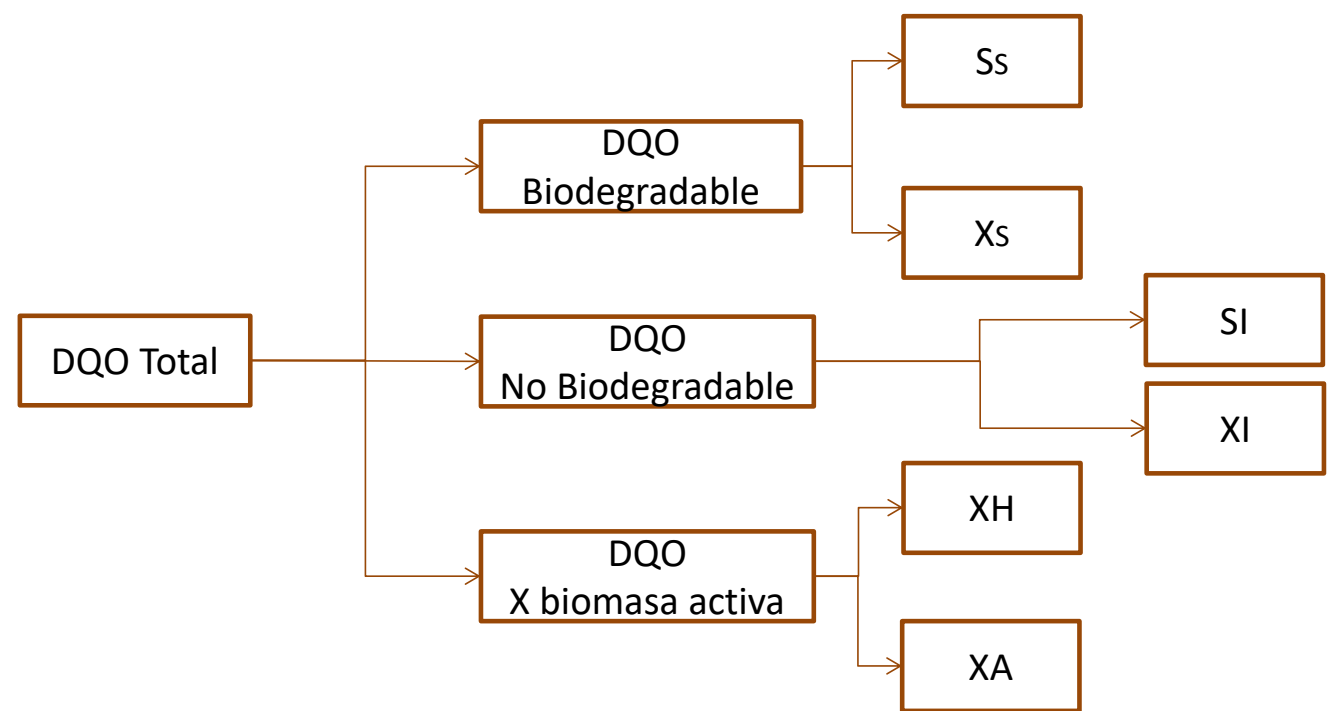

Figura 1. Fraccionamiento de la DQO presente en el ARU.

Tal y como se muestra en la figura 1, la parte biodegradable está dividida en una fracción rápidamente biodegradable soluble $\left(\mathrm{S}_{\mathrm{S}}\right)$ y en una fracción lentamente biodegradable particulada $\left(\mathrm{X}_{\mathrm{S}}\right)$. Se toma como hipótesis que la fracción rápidamente biodegradable está compuesta de materia orgánica soluble que se absorben y metabolizan rápidamente los microorganismos, mientras que la fracción particulada $\left(\mathrm{X}_{\mathrm{S}}\right)$ compuesta de partículas coloides y materia orgánica compleja sufre una hidrólisis enzimática antes de poder ser absorbida. A su vez, la materia orgánica soluble $\left(\mathrm{S}_{\mathrm{S}}\right)$ rápidamente biodegradable está compuesta de ácidos volátiles o productos de la fermentación anaerobia $\left(\mathrm{S}_{\mathrm{A}}\right)$ y materia orgánica fermentable fácilmente biodegradable $\left(\mathrm{S}_{\mathrm{F}}\right)$.

La fracción lentamente biodegradable incluye compuestos orgánicos solubles difícilmente biodegradables que se tratan como si fuera materia particulada. La fracción no biodegradable de la DQO está dividida en una fracción soluble inerte $\left(\mathrm{S}_{\mathrm{I}}\right)$ y en una fracción particulada $\left(\mathrm{X}_{\mathrm{I}}\right)$ como se muestra en la figura 1. Por lo tanto, siempre que se asuma que la concentración de microorganismos en el AR es despreciable, la DQO total se puede expresar mediante las siguientes ecuaciones $(1-4)$ :

$$
\begin{array}{ll}
\mathrm{DQO}=\mathrm{DQO}_{\text {SOLUBLE }}+\mathrm{DQO}_{\text {PARTICULADA }} & \text { Ec. (1) } \\
\mathrm{DQO}_{\text {SOLUBLE }}=\mathrm{S}_{\mathrm{S}}+\mathrm{S}_{1}=\mathrm{S}_{\mathrm{a}}+\mathrm{S}_{\mathrm{F}}+\mathrm{S}_{1} & \text { Ec. (2) } \\
\mathrm{DQO} \mathrm{P}_{\text {PARTICULADA }}=\mathrm{X}_{1}+\mathrm{X}_{\mathrm{S}} & \text { Ec. (3) } \\
\mathrm{DQO}=\mathrm{S}_{\mathrm{a}}+\mathrm{S}_{\mathrm{F}}+\mathrm{S}_{\mathrm{I}}+\mathrm{X}_{\mathrm{S}}+\mathrm{X}_{1} & \text { Ec. (4) }
\end{array}
$$




\subsection{Fraccionamiento del Nitrógeno}

El nitrógeno total $(\mathrm{N})$ presente en el ARU hace parte esencial en los procesos biológicos ya que actúa como nutriente encontrándose en diferentes formas $\left(\mathrm{N}\right.$ orgánico, $\mathrm{NH}_{4}{ }^{+}, \mathrm{NO}_{3}{ }^{-}$y $\left.\mathrm{NO}_{2}{ }^{-}\right)$y permitiendo que se lleven a cabo los procesos metabólicos. Se encuentra en su gran mayoría en forma de amonio $\left(\mathrm{NH}_{4}^{+}\right)$y nitrógeno orgánico en proporciones de un 60 y $40 \%$ respectivamente, mientras que las formas nitritos $\left(\mathrm{NO}_{2}{ }^{-}\right)$y nitratos $\left(\mathrm{NO}_{3}{ }^{-}\right)$es inferior al 1\% (EPA, 1993).

El $\mathrm{NH}_{4}{ }^{+}$proviene principalmente de las heces humanas (urea y aminoácidos), mientras que las formas oxidadas $\mathrm{NO}_{2}^{-}$y $\mathrm{NO}_{3}{ }^{-}$que son minoritarias provienen de actividades industriales y de la oxidación del amonio. La fracción del nitrógeno total incluye por un lado los nitratos y nitritos $\left(\mathrm{NO}_{\mathrm{x}}^{-}\right)$y por otro el nitrógeno total Kjeldhal (NKT). El NKT se fragmenta en nitrógeno amoniacal ( $\mathrm{NHX}$, que incluye el $\mathrm{NH}_{4}{ }^{+}$y $\mathrm{NH}_{3}$ ), nitrógeno orgánico y nitrógeno contenido en la biomasa. El nitrógeno orgánico se divide en una fracción soluble y otra particulada. Las ecuaciones $(5-7)$ que describen el fraccionamiento del $\mathrm{N}$ se muestran a continuación:

$$
\begin{array}{ll}
N_{\text {TOTAL }}=N_{\text {SOLUBLE }}(S)+N_{\text {PARTICULADO }}(X) & \text { Ec. (5) } \\
N_{\text {SOLUBLE }}=S_{N_{3}}+S_{N_{4}}+N_{\text {ORGANICO }} & \text { Ec. (6) } \\
N_{\text {PARTICULADO }}=N_{\text {TOTAL }}-N_{\text {SOLUBLE }} & \text { Ec. }(7)
\end{array}
$$

\subsection{Fraccionamiento del Fósforo}

El fósforo presente en aguas residuales proviene en su mayoría de la materia fecal $(50 \%)$, vertidos alimenticios y de los compuestos de fosfato inorgánico presente en los detergentes y productos de limpieza (30$35 \%$ ). El fósforo se puede encontrar en tres formas: ortofosfato $\mathrm{PO}_{4}{ }^{3-}$, fósforo orgánico y polifosfato $\mathrm{P}_{2} \mathrm{O}_{7}$. $\mathrm{El}$ fósforo total ( $\mathrm{P}_{\text {TOTAL }}$ ) de un $\mathrm{AR}$ se divide en dos componentes fósforo soluble $\mathrm{S}_{\mathrm{P}} \mathrm{y}$ particulado $\mathrm{X}_{\mathrm{P}}$. El fósforo soluble $S_{\mathrm{P}}$ incluye los ortofosfatos y una parte de polifosfatos siendo las más representativa en forma soluble el ortofosfato, la fracción particulada incluye el fósforo orgánico y los polifosfatos. Las ecuaciones (8 y 9) que permiten calcular cada una de las fracciones mencionadas se muestran a continuación:

$$
\begin{array}{ll}
\mathrm{P}_{\text {TOTAL }}=S_{\mathrm{P}}+\mathrm{X}_{\mathrm{P}} & \text { Ec. (8) } \\
\mathrm{S}_{\mathrm{P}}=\mathrm{S}_{\mathrm{PO} 4}+\mathrm{S}_{\mathrm{P}_{\mathrm{ORG}}} & \text { Ec. (9) }
\end{array}
$$

\subsection{Modelación de procesos biológicos}

En la actualidad las investigaciones científicas realizadas se han radicado en expresar los procesos que se llevan a cabo en el tratamiento de aguas residuales mediante modelos. El desarrollo de modelos ha permitido entender mejor los procesos y el comportamiento de los microorganismos en los distintos sistemas. Un modelo es el conjunto de ecuaciones matemáticas que describen un proceso basadas en formulaciones teóricas con sentido físico. El desarrollo de un modelo requiere de la comprobación, simulación y calibración del mismo con el fin de obtener predicciones de las variables más importantes en el proceso así como definir los parámetros característicos del mismo.

Uno de los modelos desarrollados para fangos activados es conocido con las siglas (ASM) del inglés “ Activated Sludge Model", actualmente existen hoy cuatro generaciones de modelos ASM desarrollados por el grupo de modelación de procesos de fangos activados ("Task Group on Mathematical Modelling for Design and Operation of Activated Sludge Process") perteneciente a la International Water Association (IWA), donde inicialmente pretendían describir los procesos de eliminación de materia orgánica, nitrificación y desnitrificación. La primera versión conocida es el modelo ASM1 (Henze et al., 1987) y el muy reciente ASM3 (Henze et al., 2000), capaces de predecir la degradación de la materia orgánica, nitrificación y desnitrificación en fangos activados, sin incluir el proceso de eliminación biológica de fósforo. 
El ASM2 y su versión modificada ASM2d desarrollados entre 1995 y 1999 por la IWA siendo una modificación de los modelos anteriores incluyen la remoción biológica de fósforo llevado a cabo por las bacterias acumuladoras de fosfato PAO (polyphosphate accumulating organisms).

Los componentes de los modelos propuestos por la IWA ha sido descritos por Henze et al., 2000. Uno de los desarrollos más significativos, logrado para mejorar la comprensión del proceso de fangos activados según el modelo ASM2d fue la adopción de la DQO como componente modelo para el sustrato. El grupo de modelación de la (IWA) propuso utilizar la demanda química de oxígeno DQO, porque primero es el único que permite establecer una relación clara entre los equivalentes de electrones del sustrato orgánico, la biomasa activa y el oxígeno utilizado (Henze et al., 1987, Sözen et al., 1998).

Existen diversos grupos de investigación dedicados a la modelación de los procesos biológicos los cuales generan modificaciones a los modelos propuestos por el IWA con el fin de describir mejor los procesos químicos, físicos y biológicos. El grupo de investigación Calagua de la Universidad Politécnica de Valencia en España, desarrollo el modelo BNRM1 (Biological Nutrient Removal $N^{\circ} 1$ ). Este modelo considera en total 27 componentes, 13 solubles y 14 particulados. En total el modelo BNRM1 incluye 30 procesos y supone que los realizan tres clases de microorganismos: las bacterias autótrofas, las bacterias heterótrofas y las bacterias acumuladores de polifosfatos PAO (Seco et al., 2004).

\subsection{Análisis estadístico}

El análisis estadístico desarrollado en este trabajo se realizó utilizando los conceptos de la estadística descriptiva referida a la recolección, clasificación, síntesis, organización, análisis e interpretación de los datos experimentales y componentes obtenidos en las caracterizaciones de ARU. El tratamiento de estos datos se realizó mediante la clasificación, predicción, agrupamiento y estimación de datos. En el presente trabajo el estudio estadístico cuenta con datos experimentales y componentes obtenidos en caracterizaciones de ARU en 22 depuradoras. Se utilizó para el estudio estadístico el software SPSS (Statistical Package for the Social Sciences). El análisis estadístico se organizó según los pasos descritos en la Figura 2.

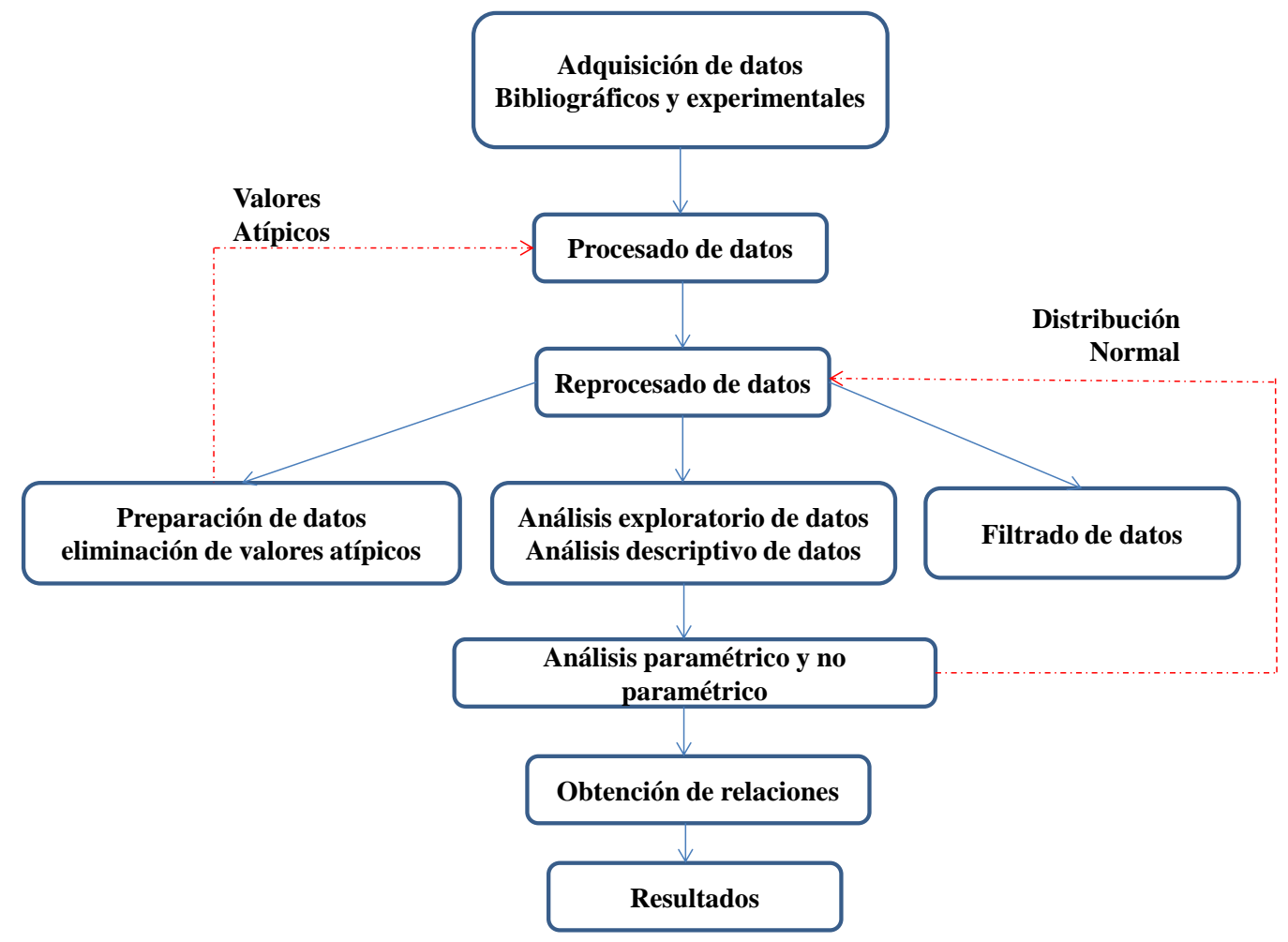

Figura 2. Acciones del proceso de análisis de datos. 


\subsection{Métodos analíticos}

El estudio experimental del presente trabajo fue realizado por el grupo de investigación CALAGUA en 22 depuradoras (EDAR) de la Comunidad Valenciana, los datos fueron procesados y tratados estadísticamente. Las técnicas analíticas utilizadas para la caracterización del ARU corresponden a las descritas en el Standard Methods (APHA, 2005), excepto la determinación de los ácidos grasos volátiles que se realizó utilizando el método acido-base propuesto por Moosbrugger et al., (1992).

\section{Resultados}

\subsection{Caracterización del ARU}

Los puntos de muestreo fueron definidos según datos obtenidos por el grupo CALAGUA, las caracterizaciones utilizadas corresponden a estudios realizados en los últimos años en la distintas EDAR de la zona comprendiendo un amplio número de depuradoras distribuidas en las tres provincias de la Comunidad Valenciana y Murcia. En total se analizaron muestras de 22 depuradoras. La Tabla 1 muestra los valores medios obtenidos en los análisis realizados.

Tabla 1. Valores medios de los parámetros convencionales analizados en las 22 depuradoras.

\begin{tabular}{|c|c|c|c|c|c|c|c|c|c|c|c|c|}
\hline \multirow[b]{2}{*}{ Depuradora } & \multirow[b]{2}{*}{$\mathbf{N}^{\circ}$ Datos } & \multicolumn{11}{|c|}{ Parametros $(\mathrm{mg} / \mathrm{l})$} \\
\hline & & DQO total & DQO sol & DBO5 & DBO5 sol & NT & $\mathrm{N}-\mathrm{NO3}$ & $\mathrm{N}-\mathrm{NH} 4$ & PT & P-PO4 & SST & SSV \\
\hline D1 & 6 & 724,5 & 149,2 & 383,0 & 95,8 & 54,0 & 0,0 & 39,8 & 8,0 & 6,0 & 392,0 & 282,0 \\
\hline D2 & 7 & 1170,0 & 464,5 & 777,0 & 292,2 & 82,0 & $<0,8$ & 61,0 & 13,2 & 8,6 & 476,0 & 362,0 \\
\hline D3 & 1 & 551,0 & 391,2 & 298,0 & 216,9 & 39,1 & 0,0 & 30,7 & 4,2 & 1,6 & 110,0 & 86,0 \\
\hline D4 & 1 & 1279,0 & 639,5 & 870,0 & 391,5 & 104,0 & - & - & 20,2 & 9,1 & 397,0 & 317,6 \\
\hline D5 & 3 & 681,0 & 539,4 & 445,0 & 347,1 & 8,5 & 0,0 & 1,0 & 3,5 & 0,3 & 179,0 & 112,0 \\
\hline D6 & 1 & 827,0 & 322,5 & 360,0 & - & 49,4 & 0,2 & 32,3 & 3,2 & 0,4 & 404,0 & 298,0 \\
\hline D7 & 1 & 1275,0 & 395,3 & 680,0 & 299,2 & 179,0 & - & - & 25,0 & 9,8 & 605,0 & 453,8 \\
\hline D8 & 3 & 290,0 & 95,7 & 151,0 & 58,9 & 49,5 & 0,0 & 32,4 & 6,9 & 4,5 & 115,0 & 97,0 \\
\hline D9 & 4 & 879,6 & 387,0 & 467,6 & 224,4 & 71,6 & 0,2 & 24,7 & 17,9 & 11,5 & 383,6 & 303,0 \\
\hline D10 & 1 & 625,5 & 356,5 & 448,0 & 246,4 & 77,6 & 0,2 & 61,9 & 7,1 & 5,1 & 129,0 & 111,0 \\
\hline D11 & 1 & 722,0 & 332,1 & 470,0 & 202,1 & 55,0 & - & - & 5,3 & 2,5 & 229,0 & 176,3 \\
\hline D12 & 3 & 539,0 & 226,4 & 380,0 & 163,4 & 50,0 & - & - & 5,8 & - & 200,0 & 158,0 \\
\hline D13 & 4 & 375,0 & 243,8 & 262,0 & 152,0 & 55,3 & - & 42,2 & 6,9 & 4,0 & 78,6 & 70,0 \\
\hline D14 & 3 & 759,5 & 181,5 & 297,5 & 75,3 & 34,2 & 3,3 & 19,4 & 5,7 & 3,2 & 309,5 & 262,5 \\
\hline D15 & 10 & 450,3 & 279,2 & 292,6 & 183,5 & 56,0 & - & 56,6 & 7,6 & 5,4 & 98,6 & 72,0 \\
\hline D16 & 1 & 257,8 & 59,0 & 231,0 & 97,0 & 38,7 & $<0,2$ & 25,7 & 5,4 & 3,5 & 87,1 & 70,3 \\
\hline D17 & 1 & 694,0 & 388,6 & 436,0 & 292,1 & 83,0 & 0,0 & 68,4 & 27,5 & 18,7 & 171,0 & 152,0 \\
\hline D18 & 1 & 377,0 & 173,4 & 217,0 & 132,4 & 48,6 & 0,0 & 41,4 & 9,6 & 6,6 & 136,0 & 115,0 \\
\hline D19 & 1 & 738,0 & 273,1 & 500,0 & 260,0 & 97,0 & 0,0 & - & 14,1 & 9,2 & 198,0 & 158,0 \\
\hline D20 & 1 & 361,0 & 205,8 & 255,0 & 114,8 & 65,0 & - & - & 8,7 & 3,5 & 117,0 & 101,0 \\
\hline D21 & 1 & 422,0 & 198,3 & 259,0 & 121,2 & 56,0 & 0,0 & 40,8 & 9,9 & 5,9 & 143,0 & 117,0 \\
\hline D22 & 1 & 691,0 & 324,8 & 585,0 & 275,0 & 65,0 & - & - & 6,8 & 3,7 & 230,0 & 172,0 \\
\hline
\end{tabular}

En los datos presentados anteriormente se pueden observar los valores medidos en cada punto de muestreo. Esta caracterización permite tener una idea del tipo de ARU a tratar. Algunos valores difieren de los encontrados como ARU debido a diferencias en el punto de muestreo o la influencia de ARU de origen industrial. La caracterización del ARU según los modelos matemáticos para ARU incluye el fraccionamiento de los datos experimentales en las fracciones solubles, particuladas e inertes presentes en el agua. Estas fracciones permiten establecer criterios para el diseño y la simulación de nuevos procesos.

En la Tabla 2 se presentan los principales componentes en las que es posible separar el ARU utilizada en los modelos de fangos activados. Estos componentes se obtienen mediante los balances mostrados en las ecuaciones 4,7 y 9, empleando los datos obtenidos a partir de los datos experimentales de la tabla 1. Este fraccionamiento incluye las distintas formas en las que es posible encontrar los contaminantes presentes en el agua, componentes solubles (S) y componentes particulados (X).

En el estudio estadístico que se desarrolló en el presente trabajo se utilizaron los datos experimentales obtenidos en las distintas caracterizaciones realizadas en las EDAR seleccionadas. En el analisis desarrollado se obtuvieron relaciones estadísticamente significativas, para ello se aplicaron distintas pruebas estadisticas que permitieron eliminar datos atípicos, fuera de rango y aquellos que no eran representativos. 
Las pruebas estadísticas realizadas una vez concluida la fase correspondiente al reprocesado de datos fueron: la prueba T-Student para determinar si existe diferencia significativa entre los valores medios de las dos categorías propuestas. Pruebas estadísticas de Pearson y Spearman para determinar la correlación existente entre los diferentes datos experimentales y componentes del modelo.

Tabla 2. Componentes del AR obtenidos a partir de datos experimentales.

\begin{tabular}{|c|c|c|c|c|c|c|c|c|c|c|}
\hline \multirow[b]{2}{*}{ Depuradora } & \multicolumn{10}{|c|}{ Componentes (mg/l) } \\
\hline & Ss & $\mathbf{S a}$ & Sf & Xs & XI & SI & Xnv & SNH4 & SPO4 & SALK \\
\hline D1 & 134,1 & 57,2 & 76,8 & 350,7 & 227,3 & 16,3 & 119,7 & 40,9 & 5,8 & 3,2 \\
\hline D2 & 382,5 & 214,2 & 168,2 & 636,1 & 85,4 & 103,3 & 98,0 & 61,1 & 8,6 & 5,1 \\
\hline D3 & 334,2 & 61,4 & 272,8 & 101,8 & 58,0 & 57,0 & 24,0 & 30,7 & 1,6 & 3,7 \\
\hline D4 & - & - & - & - & - & - & 79,4 & - & 9,1 & - \\
\hline D5 & 460,8 & 166,9 & 405,2 & 69,5 & 64,1 & 39,5 & 64,3 & 1,0 & 0,4 & 6,9 \\
\hline D6 & 206,4 & 66,2 & 140,1 & 245,6 & 258,0 & 117,0 & 106,0 & 32,3 & 0,4 & 5,0 \\
\hline D7 & - & - & - & - & - & - & 151,3 & - & 9,8 & - \\
\hline D8 & 68,0 & 4,9 & 63,1 & 138,0 & 56,0 & 28,0 & 18,0 & 32,4 & 4,5 & 4,3 \\
\hline D9 & 378,3 & 85,9 & 349,6 & 334,4 & 149,3 & 17,7 & 80,7 & 24,8 & 11,5 & 8,7 \\
\hline D10 & 301,8 & 91,4 & 271,3 & 226,2 & 36,7 & 48,7 & 18,0 & 62,0 & 5,1 & 8,7 \\
\hline D11 & - & - & - & - & - & - & 45,8 & - & 2,5 & - \\
\hline D12 & - & - & - & - & - & - & 68,0 & - & 0,0 & - \\
\hline D13 & 154,2 & 52,3 & 136,7 & 157,2 & 53,7 & 97,7 & 8,7 & 42,2 & 4,0 & 8,3 \\
\hline D14 & 104,5 & 21,3 & 89,9 & 284,8 & 320,7 & 43,0 & 47,0 & 19,4 & 3,2 & 5,3 \\
\hline D15 & 243,2 & 81,7 & 215,9 & 110,8 & 61,0 & 35,3 & 26,7 & 56,6 & 5,4 & 7,8 \\
\hline D16 & 92,4 & 46,4 & 73,8 & 95,7 & 44,1 & 25,6 & 16,8 & 25,7 & 3,5 & 3,6 \\
\hline D17 & 345,6 & 154,7 & 191,0 & 215,4 & 90,0 & 43,0 & 19,0 & 68,4 & 18,7 & 5,0 \\
\hline D18 & 145,8 & 16,2 & 129,6 & 127,2 & 73,0 & 31,0 & 21,0 & 41,4 & 6,6 & 3,7 \\
\hline D19 & - & - & - & - & - & - & 59,4 & - & 9,2 & - \\
\hline D20 & - & - & - & - & - & - & 23,4 & - & 3,5 & - \\
\hline D21 & 168,9 & 24,7 & 144,1 & 179,1 & 42,0 & 32,0 & 26,0 & 40,8 & 5,9 & 5,0 \\
\hline D22 & - & - & - & - & - & - & 39,6 & - & 3,7 & - \\
\hline
\end{tabular}

Algunas de las relaciones que se presentan en este trabajo han sido propuestas en diversos estudios desarrollados sobre el tratamiento de aguas residuales como el realizado por (Orhon et al.,1996), en este estudio se caracterizaron las aguas residuales de la ciudad de Istanbul (Turquía), se muestran las relaciones existentes entre las distintas fracciones de la Demanda Química de Oxigeno (DQO), Demanda Biológica de Oxígeno (DBO), N y P. Otros estudios sobre la caracterización del AR que citan relaciones entre los parámetros han sido hechos por el Grupo de Modelación Matemática en Fangos activados de la IWA, durante los trabajos desarrollados para la obtención de los distintos modelos existentes.

\subsection{Relaciones matemáticas estudiadas}

La estimación de los parámetros para la caracterización de un AR según los modelos de simulación ASM1, ASM2d y BNRM1, requieren de relaciones y consideraciones que permitan obtener todos los componentes de una manera sistemática y científica. Teniendo en cuenta que la caracterización del ARU pretende interpretar la tratabilidad de las aguas residuales, dicha tratabilidad es observada utilizando datos experimentales como la DQO, DBO, N y P. Estos datos dan una idea del contenido total de materia orgánica y nutrientes presentes en el ARU analizada. La información aportada por estos datos es indispensable como punto de partida en cualquier estudio sobre las aguas residuales.

Uno de los parámetros importantes en el diseño de nuevos procesos que determinan la cantidad de materia orgánica biodegradable presente en las aguas residuales se conoce como índice de biodegrabilidad, este índice es una relación entre datos experimentales que permite determinar el grado de tratabilidad de las aguas residuales, algunos autores citan la relación (DBO: DQO) como el índice de biodegrabilidad donde la DBO puede estar expresada en términos de DBO5 o DBOLIM. En los Estados Unidos (EE.UU.) composiciones típicas para ARU de concentración débil, medio y fuertes corresponden a una gama entre 0.40-0.44 para este cociente (Metcalf y Eddy, 1991). Otra relación importante que permite establecer la cantidad de materia orgánica total biodegradable es la relación (DBO5: DBOLIM), tradicionalmente se han utilizado valores entre 0.67-0.7 para este cociente o inclusive 0.6 propuesto por Henze et al., 1996. Otras importantes relaciones como la (DQO: N), (DQO: P), (DBO5: N) y (DBO5: P) permiten fijar los parámetros para el diseño y simulación de 
los procesos de nitrificación, desnitrificación y eliminación biológica de fósforo. Asimismo y con el fin de obtener todos los componentes del modelo, en el presente trabajo se proponen diversas relaciones que permitan calcular las diferentes fracciones existentes en los modelos de fangos activados más utilizados por la comunidad científica y en particular el modelo BNRM1.

Para la aplicación de los modelos matemáticos en el tratamiento de aguas residuales se requiere de la caracterización detallada sobre la composición de las aguas, siendo necesario calcular los componentes a partir de los datos experimentales haciendo uso de herramientas que faciliten el fraccionamiento del ARU. Una herramienta útil que facilita la caracterización del ARU, son las relaciones matemáticas tipo I y II entre datos experimentales y componentes como las que se muestran en la Tabla 3.

Tabla 3. Relaciones propuestas entre los datos. Tipo I y II.

\begin{tabular}{|c|c|}
\hline TIPO I & TIPO II \\
\hline $\begin{array}{c}\text { Relaciones entre } \\
\text { datos } \\
\text { experimentales }\end{array}$ & $\begin{array}{c}\text { Relaciones entre } \\
\text { componentes y } \\
\text { datos } \\
\text { experimentales }\end{array}$ \\
\hline $\mathrm{DBO}_{\mathrm{LIM}}: \mathrm{DQO}$ & SS:DQO \\
\hline $\mathrm{DBO}_{5}: \mathrm{DQO}$ & $\mathrm{S}_{\mathrm{F}}: \mathrm{DQO}_{\mathrm{SOL}}$ \\
\hline DQO:N & $S_{1}: D Q O$ \\
\hline DQO:P & $\mathrm{X}_{\mathrm{S}}: \mathrm{DQO}$ \\
\hline DQO:SSV & $\mathrm{X}_{1}: \mathrm{DQO}$ \\
\hline SSV:SST & Sa:DQO \\
\hline $\mathrm{DBO}_{5}: \mathrm{DBO}_{\text {LIM }}$ & $S_{F}: D Q O$ \\
\hline $\mathrm{DBO}_{5}: \mathrm{N}$ & Ss:DBOLIM \\
\hline $\mathrm{DBO}_{5}: \mathrm{P}$ & $\mathrm{X}_{\mathrm{s}}$ :DBOLIM \\
\hline $\mathrm{NH}_{4}{ }^{+}: \mathrm{N}$ & \\
\hline $\mathrm{NT}_{\text {SOL }}: \mathrm{N}$ & \\
\hline $\mathrm{PO}_{4}{ }^{-3}: \mathrm{PT}$ & \\
\hline DBO $_{\text {LIMSO }} \mathrm{L}: \mathrm{DBO}_{\text {LIM }}$ & \\
\hline $\mathrm{DQO}_{\mathrm{SO}}: \mathrm{DQO}$ & \\
\hline $\mathrm{DBO}_{5 \mathrm{SOL}}: \mathrm{DBO}_{5}$ & \\
\hline
\end{tabular}

\subsection{Análisis estadístico}

El análisis exploratorio inicial se realizó con un promedio de 56 muestras tomadas en 22 EDAR con las cuales se determinaron las distintas medidas de tendencia central descritas anteriormente, con estos datos es posible observar la distribución de los datos con respecto al valor medio e inferir sobre el comportamiento que tiene la muestra.

Los valores de Asimetría y Curtosis calculados para cada relación, permiten observar el grado de acumulación de los datos alrededor de la media y la inclinación de la curva comparada con una muestra normal, se pueden distinguir 3 distribuciones típicas según el grado de concentración de los datos alrededor de la media, es decir si los 45 datos se concentran demasiado o no, comparados con un modelo de distribución llamado distribución normal.

El análisis estadístico fue realizado para los datos experimentales de las tablas 1 y 2 del presente trabajo, los valores que se presentan a continuación corresponden a los valores medios obtenidos y representan las características de un ARU en la Comunidad Valenciana. Sin embargo este análisis inicial no permite establecer si todos los datos son representativos o existen datos atípicos en la muestra.

Para identificar los valores atípicos para cada uno de los parámetros se utilizó la herramienta gráfica conocida como diagramas de caja incluida dentro de la herramienta informática SPSS. Estos diagramas permiten identificar la distribución y la dispersión de los datos de una variable. Es un gráfico, basado en cuartiles, 
mediante el cual se visualiza un conjunto de datos alrededor de la media. La tabla 4 muestra el análisis estadístico inicial realizado a los datos, empleando toda la información de la tabla 1.

Los datos que se presentan en la tabla 5 han sido tomados y tratados a partir de la tabla 2 del presente trabajo, constituyen el fraccionamiento de los datos de la DQO, $\mathrm{N}$ y $\mathrm{P}$ medidos en el agua influente a cada depuradora.

Tabla 4. Valores medios de los datos experimentales utilizados en este estudio.

\begin{tabular}{|c|c|c|c|c|c|c|c|c|}
\hline \begin{tabular}{|l|} 
Datos \\
experimentales
\end{tabular} & $\begin{array}{c}\text { DQO } \\
(\mathrm{mg} \mathrm{O} / \mathrm{l}) \\
\end{array}$ & \begin{tabular}{|c|} 
DBO5 (mg \\
O/l) \\
\end{tabular} & \begin{tabular}{|c|}
$\begin{array}{c}\text { DBOLIM } \\
(\mathrm{mg} \mathrm{O} / \mathrm{l})\end{array}$ \\
\end{tabular} & $\begin{array}{c}\text { SST } \\
(\mathrm{mg} / \mathrm{l}) \\
\end{array}$ & $\begin{array}{c}\text { SSV } \\
(\mathrm{mg} / \mathrm{l}) \\
\end{array}$ & \begin{tabular}{|c|}
$\mathbf{N}$ \\
$(\mathrm{mgN} / \mathrm{l})$
\end{tabular} & $\begin{array}{c}\mathrm{NH4} \\
(\mathrm{mgN} / \mathrm{l}) \\
\end{array}$ & $\begin{array}{c}\mathbf{P} \\
(\mathrm{mgP} / \mathrm{l}) \\
\end{array}$ \\
\hline $\mathbf{N}$ & 56 & 49 & 48 & 56 & 56 & 56 & 49 & 56 \\
\hline Media & 655,7 & 430,3 & 477,2 & 242,1 & 187,5 & 59,6 & 38,1 & 8,8 \\
\hline Mediana & 653,5 & 380,0 & 440,5 & 188,5 & 142,5 & 55,5 & 38,4 & 7,0 \\
\hline Moda & 138,0 & 151,0 & 109,0 & 57,0 & 54,0 & 39,0 & 60,0 & 8,0 \\
\hline Desv Típ & 331,2 & 206,7 & 282,9 & 161,0 & 124,3 & 29,2 & 19,9 & 5,3 \\
\hline \begin{tabular}{|l|} 
Asimetria (A) \\
\end{tabular} & 0,6 & 1,2 & 1,2 & 0,7 & 0,8 & 1,3 & 0,5 & 1,8 \\
\hline \begin{tabular}{|l|} 
Error $(\mathbf{A})$ \\
\end{tabular} & 0,3 & 0,3 & 0,3 & 0,3 & 0,3 & 0,3 & 0,3 & 0,3 \\
\hline \begin{tabular}{|l|} 
Curtosis $(\mathrm{C})$ \\
\end{tabular} & 0,2 & 1,2 & 15,4 & $-0,7$ & $-0,4$ & 4,4 & 0,4 & 3,0 \\
\hline Error (C) & 0,6 & 0,7 & 0,7 & 0,6 & 0,6 & 0,6 & 0,7 & 0,6 \\
\hline Mínimo & 138,0 & 151,0 & 88,0 & 55,0 & 41,0 & 2,0 & 0,2 & 3,2 \\
\hline Máximo & 1630,0 & 1073,0 & 1370,0 & 624,0 & 494,0 & 179,0 & 95,3 & 27,5 \\
\hline 25 & 402,5 & 277,5 & 287,5 & 114,0 & 88,8 & 39,2 & 23,7 & 5,3 \\
\hline 50 & 653,5 & 380,0 & 440,5 & 188,5 & 142,5 & 55,5 & 38,4 & 7,0 \\
\hline 75 & 820,7 & 500,5 & 561,0 & 366,0 & 293,5 & 74,8 & 48,4 & 9,9 \\
\hline
\end{tabular}
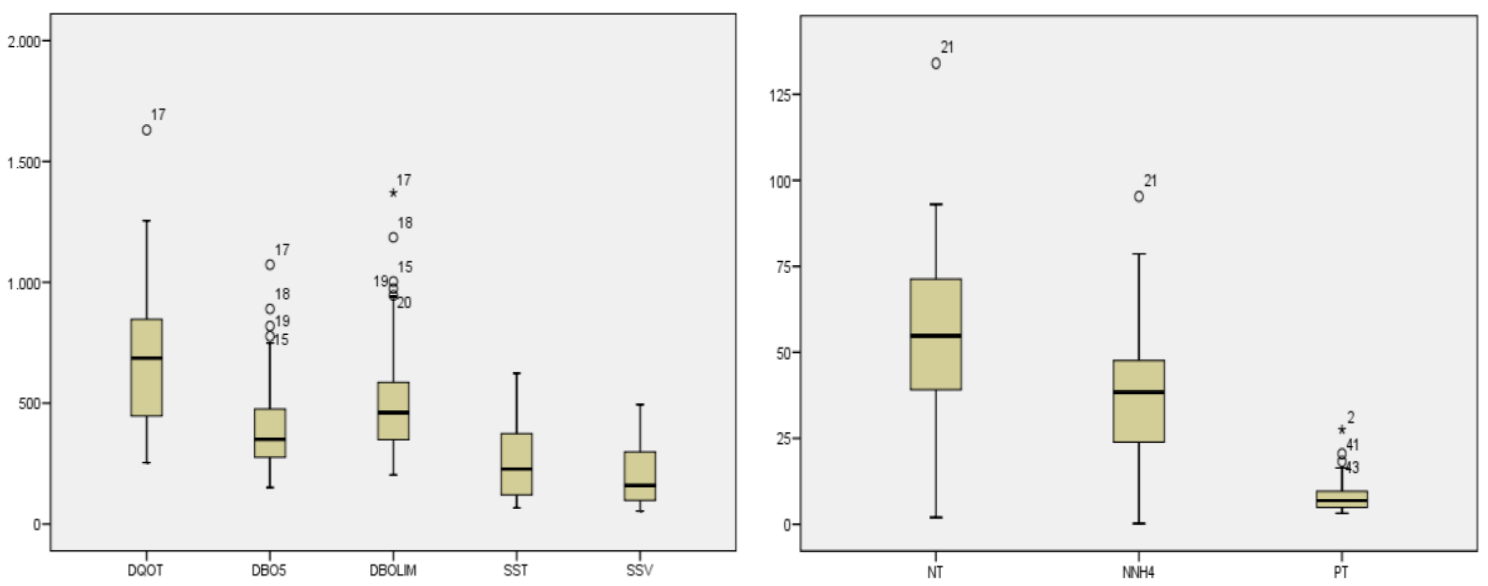

Figura 3. Ejemplo del diagrama de caja para los datos experimentales obtenidos en la tabla 4.

Tabla 5. Valores de tendencia central de los componentes del modelo.

\begin{tabular}{|c|c|c|c|c|c|c|c|c|c|}
\hline $\begin{array}{l}\text { Datos } \\
\text { experimentales }\end{array}$ & $\begin{array}{c}\mathrm{SS} \\
(\mathrm{mg} \mathrm{O/l})\end{array}$ & $\begin{array}{c}\text { Sa } \\
(\mathbf{m g ~ O / l})\end{array}$ & $\begin{array}{c}\text { SF } \\
(\mathbf{m g ~ O / l})\end{array}$ & $\begin{array}{c}\mathrm{Xs} \\
(\mathrm{mg} / \mathrm{l})\end{array}$ & $\begin{array}{c}\mathbf{X I} \\
(\mathbf{m g} / \mathbf{l})\end{array}$ & $\begin{array}{c}\mathrm{SI} \\
(\mathrm{mgN} / \mathrm{l})\end{array}$ & $\begin{array}{c}\text { SNH4 } \\
(\mathrm{mgN} / \mathrm{l})\end{array}$ & $\begin{array}{c}\text { SPO4 } \\
(\mathrm{mgP} / \mathrm{l})\end{array}$ & $\begin{array}{c}\text { XNV } \\
(\mathrm{mg} / \mathrm{l})\end{array}$ \\
\hline $\mathbf{N}$ & 47 & 32 & 47 & 47 & 44 & 47 & 49 & 56 & 56 \\
\hline Media & 225,50 & 91,20 & 164,30 & 252,30 & 116,40 & 47,45 & 38,28 & 5,39 & 54,53 \\
\hline Mediana & 168,80 & 61,10 & 129,50 & 215,00 & 62,00 & 35,60 & 38,50 & 4,95 & 39,28 \\
\hline Moda & 8,49 & 52,20 & 8,49 & 71,00 & 58,00 & 40,00 & 60,50 & 3,00 & 14,00 \\
\hline Desv Típ & 147,00 & 82,20 & 122,00 & 190,90 & 116,70 & 47,65 & 19,93 & 3,53 & 42,40 \\
\hline Asimetria (A) & 0,74 & 1,20 & 1,41 & 1,10 & 1,76 & 2,05 & 0,45 & 1,18 & 0,71 \\
\hline Error (A) & 0,35 & 0,41 & 0,35 & 0,35 & 0,36 & 0,35 & 0,34 & 0,32 & 0,32 \\
\hline Curtosis (C) & $-0,26$ & 0,11 & 1,74 & 0,56 & 2,71 & 3,81 & 0,42 & 2,58 & $-0,67$ \\
\hline Error $(\mathbf{C})$ & 0,68 & 0,81 & 0,68 & 0,68 & 0,70 & 0,68 & 0,67 & 0,63 & 0,63 \\
\hline Mínimo & 8,49 & 4,90 & 8,49 & 31,00 & 2,00 & 0,00 & 0,20 & 0,00 & 4,00 \\
\hline Máximo & 607,17 & 266,00 & 522,90 & 762,80 & 513,00 & 202,00 & 95,30 & 18,70 & 154,00 \\
\hline 25 & 116,63 & 37,60 & 78,00 & 99,43 & 47,75 & 16,10 & 23,70 & 3,00 & 18,25 \\
\hline 50 & 168,87 & 61,10 & 129,50 & 215,00 & 62,00 & 35,60 & 38,50 & 4,95 & 39,28 \\
\hline 75 & 334,21 & 138,00 & 238,00 & 356,10 & 158,20 & 56,00 & 48,35 & 7,30 & 89,25 \\
\hline
\end{tabular}




\subsection{Análisis estadístico para las relaciones propuestas tipo I y II}

Las relaciones entre los datos experimentales y los componentes de los modelos de fangos activados permiten caracterizar totalmente un ARU y sirven para identificar las cantidades de sustrato y nutrientes presentes en el agua influente.

Estos datos pueden ser de gran importancia, ya que permite diseñar un nuevo proceso así como identificar los requerimientos exigidos por los microorganismos para el correcto funcionamiento de una EDAR existente. Las relaciones propuestas en este estudio descritas como relaciones tipo I y tipo II permitirán calcular o predecir datos y componentes faltantes del ARU. Las relaciones tipo I permiten calcular todos los datos necesarios para completar o caracterizar totalmente un ARU.

Las relaciones tipo II pueden ser utilizadas para calcular los componentes descritos en los modelos matemáticos de fangos activados como el BNRM1. Las tablas 6, 7 y 8 muestran los resultados del análisis estadístico realizado en este trabajo para las relaciones tipo I y II calculadas a partir de los datos experimentales y los componentes utilizados en este estudio.

Tabla 6. Valores de tendencia central de las relaciones tipo I propuestas.

\begin{tabular}{|c|c|c|c|c|c|c|c|c|c|}
\hline $\begin{array}{l}\text { Relaciones } \\
\text { tipo I }\end{array}$ & $\begin{array}{c}\text { DBOLIM: } \\
\text { DQO }\end{array}$ & \begin{tabular}{c|} 
DBO5: \\
DBOLIM
\end{tabular} & $\begin{array}{l}\text { DBO5: } \\
\text { DQO }\end{array}$ & $\begin{array}{l}\text { DQO: } \\
\text { N }\end{array}$ & $\begin{array}{c}\text { DBO5: } \\
\text { N }\end{array}$ & $\begin{array}{c}\text { DBO5: } \\
\text { P }\end{array}$ & $\begin{array}{l}\text { DQO: } \\
\text { P }\end{array}$ & $\begin{array}{l}\text { DQO: } \\
\text { SSV }\end{array}$ & $\begin{array}{l}\text { SSV: } \\
\text { SST }\end{array}$ \\
\hline $\mathbf{N}$ & 48 & 42 & 49 & 56 & 49 & 49 & 56 & 49 & 56 \\
\hline Media & 0,740 & 0,780 & 0,610 & 18,200 & 12,600 & 54,700 & 85,400 & 4,070 & 0,785 \\
\hline Mediana & 0,790 & 0,780 & 0,630 & 10,200 & 6,730 & 45,500 & 67,000 & 3,600 & 0,784 \\
\hline Moda & 0,390 & 0,420 & 0,310 & 3,640 & 5,810 & 15,800 & 23,000 & 1,880 & 0,719 \\
\hline Desv Típ & 0,130 & 0,084 & 0,110 & 44,900 & 33,500 & 29,000 & 48,600 & 1,500 & 0,085 \\
\hline Asimetria (A) & $-0,980$ & $-1,200$ & $-0,730$ & 6,950 & 6,600 & 1,090 & 1,370 & 0,791 & $-0,399$ \\
\hline Error (A) & 0,340 & 360 & 0,340 & ,319 & 0,340 & ,340 & 0,319 & 40 & 0,319 \\
\hline (C) & 200 & 7,980 & $-0,020$ & 50,200 & 44,900 & 0,549 & 2,040 & 088 & 0,978 \\
\hline Err & 0,670 & 0,710 & 0,660 & 0,628 & 0,668 & 0,668 & 0,628 & 0,668 & 0,628 \\
\hline Mínimo & 0,390 & 0,420 & 0,310 & 3,640 & 2,270 & 15,800 & 23,000 & 880 & 0,522 \\
\hline Máximo & 0,940 & 1,000 & 0,840 & 340,00 & 238,00 & 132,00 & 258,00 & 8,390 & 0,947 \\
\hline 25 & 0,650 & 0,750 & 0,530 & 7,530 & 4,920 & 34,900 & 48,200 & 2,780 & 0,737 \\
\hline 50 & 0,790 & 0,780 & 0,630 & 10,200 & 6,730 & 45,500 & 67,000 & 3,600 & 0,784 \\
\hline 15 & 830 & 810 &, 700 & 13,900 & 0 &, 2 & 0, & 5,040 & , \\
\hline
\end{tabular}

\begin{tabular}{|c|c|c|c|c|c|c|}
\hline $\begin{array}{l}\text { Relaciones } \\
\text { tipo I }\end{array}$ & $\begin{array}{c}\text { DQOSOL: } \\
\text { DQO }\end{array}$ & $\begin{array}{c}\text { DBOlimsol: } \\
\text { DBOlim }\end{array}$ & $\begin{array}{l}\text { DBO5sol: } \\
\text { DBO5 }\end{array}$ & $\begin{array}{l}\text { NH4: } \\
\text { Ntsol }\end{array}$ & $\begin{array}{c}\text { Ntsol: } \\
\mathbf{N}\end{array}$ & $\begin{array}{l}\text { PO4: } \\
\text { P }\end{array}$ \\
\hline $\mathbf{N}$ & 56 & 48 & 49 & 40 & 46 & 55 \\
\hline Media & 0,457 & 0,474 & 0,462 & 0,806 & 0,819 & 0,601 \\
\hline Mediana & 0,460 & 0,468 & 0,455 & 0,882 & 0,824 & 0,647 \\
\hline Moda & 0,460 & 0,380 & 0,430 & 0,112 & 0,800 & 0,330 \\
\hline Desv Típ & 0,163 & 0,176 & 0,164 & 0,246 & 0,108 & 0,194 \\
\hline Asimetria (A) & 0,134 & 0,193 & 0,196 & $-1,239$ & $-0,380$ & $-0,980$ \\
\hline Error (A) & 0,319 & 0,343 & 0,340 & 0,374 & 0,350 & 0,322 \\
\hline Curtosis (C) & $-0,140$ & -0,763 & $-0,460$ & 1,411 & $-0,736$ & 1,100 \\
\hline Error (C) & 0,628 & 0,674 & 0,668 & 0,733 & 0,688 & 0,634 \\
\hline Mínimo & 0,100 & 0,160 & 0,160 & 0,112 & 0,584 & 0,057 \\
\hline Máximo & 0,830 & 0,850 & 0,820 & 1,26 & 0,99 & 0,93 \\
\hline 25 & 0,340 & 0,330 & 0,338 & 0,736 & 0,735 & 0,500 \\
\hline 50 & 0,460 & 0,468 & 0,455 & 0,882 & 0,824 & 0,647 \\
\hline 75 & 0,556 & \begin{tabular}{l|l|}
0,618 \\
\end{tabular} & 0,553 & 0,962 & 0,917 & 0,732 \\
\hline
\end{tabular}


Tabla 8. Valores de tendencia central de las relaciones tipo II propuestas.

\begin{tabular}{|c|c|c|c|c|c|c|c|c|c|}
\hline $\begin{array}{l}\text { Relaciones } \\
\text { tipo II }\end{array}$ & $\begin{array}{c}\text { SS: } \\
\text { DQOT }\end{array}$ & $\begin{array}{c}\text { SF: } \\
\text { DQOT }\end{array}$ & $\begin{array}{c}\text { Sa: } \\
\text { DQOT }\end{array}$ & $\begin{array}{c}\text { Sa: } \\
\text { DQOsol }\end{array}$ & $\begin{array}{c}\text { Sf: } \\
\text { DQOsol }\end{array}$ & $\begin{array}{c}\text { SI: } \\
\text { DQOsol }\end{array}$ & $\begin{array}{c}\text { Xs: } \\
\text { DQOT }\end{array}$ & $\begin{array}{c}\text { XI: } \\
\text { DQOT }\end{array}$ & $\begin{array}{c}\text { SI: } \\
\text { DQOT }\end{array}$ \\
\hline $\mathbf{N}$ & 47 & 47 & 32 & 32 & 47 & 47 & 47 & 47 & 46 \\
\hline Media & 0,360 & 0,290 & 0,110 & 0,290 & 0,610 & 0,190 & 0,370 & 0,160 & 0,090 \\
\hline \begin{tabular}{|l|} 
Mediana \\
\end{tabular} & 0,350 & 0,270 & 0,100 & 0,290 & 0,580 & 0,150 & 0,350 & 0,130 & 0,070 \\
\hline Moda & 0,020 & 0,020 & 0,006 & 0,051 & 0,040 & 0,013 & 0,087 & $-0,430$ & 0,000 \\
\hline \begin{tabular}{|l|} 
Desv Típ \\
\end{tabular} & 0,170 & 0,180 & 0,070 & 0,140 & 0,210 & 0,160 & 0,150 & 0,160 & 0,100 \\
\hline Asimetria (A) & 0,360 & 0,710 & 0,720 & 0,100 & $-0,310$ & 2,410 & 0,110 & $-0,250$ & 4,210 \\
\hline \begin{tabular}{|l|} 
Error (A) \\
\end{tabular} & 0,340 & 0,340 & 0,410 & 0,410 & 0,340 & 0,350 & 0,340 & 0,340 & 0,350 \\
\hline Curtosis (C) & \begin{tabular}{l|l|}
$-0,240$ \\
\end{tabular} & $-0,160$ & 0,310 & $-0,870$ & 0,120 & 8,500 & $-0,160$ & 4,130 & 23,100 \\
\hline Error (C) & 0,680 & 0,680 & 0,800 & 0,800 & 0,680 & 0,680 & 0,680 & 0,680 & 0,680 \\
\hline Mínimo & 0,020 & 0,020 & 0,000 & 0,050 & 0,040 & 0,013 & 0,080 & $-0,430$ & 0,004 \\
\hline Máximo & 0,760 & 0,760 & 0,310 & 0,59 & 0,98 & 0,96 & 0,73 & 0,580 & 0,660 \\
\hline 25 & 0,230 & 0,120 & 0,050 & 0,160 & 0,460 & 0,080 & 0,290 & 0,070 & 0,035 \\
\hline 50 & 0,350 & 0,270 & 0,100 & 0,290 & 0,580 & 0,150 & 0,350 & 0,130 & 0,077 \\
\hline 75 & 0,480 & 0,400 & 0,160 & 0,400 & 0,810 & 0,260 & 0,470 & 0,220 & 0,100 \\
\hline
\end{tabular}

\subsection{Relaciones tipo I y II obtenidas}

Los valores obtenidos para las relaciones propuestas se muestran en la tabla 9. A continuación se describe la influencia que tiene cada uno de los parámetros utilizados y las relaciones propuestas sobre el tratamiento de las aguas residuales.

Para la relación $\mathrm{DBO}_{5} / \mathrm{DBO}_{\text {LIM }}$, la $\mathrm{DBO}_{5}$ corresponde a una medida estándar indirecta de la materia orgánica donde la muestra es incubada durante 5 días, esta medida de la DBO no ofrece un valor total y exacto del consumo de oxigeno por parte de los microorganismo ni asegura el consumo total de materia orgánica siendo necesario someter la muestra a más tiempo de incubación el cual ha sido definido en 20 días donde se alcanza una degradación de materia orgánica alrededor del $95 \%$, la variable medida al cabo de este tiempo se conoce como $\mathrm{DBO}_{\text {LIM }}$ siendo esta medida la base de cualquier cálculo biológico. En muchas caracterizaciones debido al tiempo que requiere realizar estos ensayos se utiliza la $\mathrm{DBO}_{5}$ como parámetro principal y para pasar de $\mathrm{DBO}_{5}$ a $\mathrm{DBO}_{\text {LIM }}$ se utiliza la relación existente entre las variables $\mathrm{DBO}_{5}$ : $\mathrm{DBO}_{\mathrm{LIM}}$ con valores estándar para ARU.

Tabla 9. Resultados obtenidos para las relaciones propuestas tipo I.

\begin{tabular}{|c|c|c|}
\hline TIPO I & MEDIA & SD \\
\hline DBO $_{\text {LIM }}: \mathrm{DQO}$ & 0,75 & 0,12 \\
\hline $\mathrm{DBO}_{5}: \mathrm{DQO}$ & 0,61 & 0,11 \\
\hline DQO:N & 10,25 & 4,09 \\
\hline DQO:P & 76,02 & 34,81 \\
\hline DQO:SSV & 3,98 & 1,38 \\
\hline SSV:SST & 0,79 & 0,07 \\
\hline $\mathrm{DBO}_{5}: \mathrm{DBO}_{\mathrm{LIM}}$ & 0,77 & 0,07 \\
\hline $\mathrm{DBO}_{5}: \mathrm{N}$ & 6,65 & 2,31 \\
\hline $\mathrm{DBO}_{5}: \mathrm{P}$ & 50,13 & 23,18 \\
\hline $\mathrm{NH}_{4}{ }^{+}: \mathrm{NT}_{\mathrm{SOL}}$ & 0,88 & 0,12 \\
\hline $\mathrm{NT}_{\text {SOL }}: \mathrm{N}$ & 0,82 & 0,11 \\
\hline $\mathrm{PO}_{4}^{-3}: \mathrm{PT}$ & 0,64 & 0,14 \\
\hline DBO $_{\text {LIMSOL }}: \mathrm{DQO}$ & 0,47 & 0,17 \\
\hline $\mathrm{DQO}_{\text {SOL }}: \mathrm{DQO}$ & 0,45 & 0,16 \\
\hline $\mathrm{DBO}_{5 \mathrm{SOL}}: \mathrm{DBO}_{5}$ & 0,46 & 0,35 \\
\hline
\end{tabular}


Calcular la $\mathrm{DBO}_{\text {LIM }}$ a partir de valores de $\mathrm{DBO}_{5}$ ha sido propuesta en diversas ocasiones encontrándose valores para esta relación según Henze et al.,1992 de 0,6 a 0,7 así como valores según Orhon et al. 1996 de 0,3 a 0,7 para la relación $\mathrm{DBO}_{5}$ : $\mathrm{DBO}_{\mathrm{LIM}}$, un valor característico en ARU es de 0,65.

La biodegrabiliad de las aguas residuales puede ser medida utilizando como parámetros de medición la $\mathrm{DBO}_{\mathrm{LIM}} \mathrm{o} \mathrm{DBO}_{5}$ comparándolos con el valor de la DQO, esta relación es conocida como índice de biodegrabilidad. La relación $\mathrm{DBO}_{5} / \mathrm{DQO}$ conocida como un índice de biodegrabilidad es utilizada para determinar de forma aproximada los compuestos orgánicos presentes en las aguas residuales, puede darnos una aproximación de la materia orgánica fácilmente y lentamente biodegradable presente en el agua influente. Algunos estudios mencionan valores típicos para esta relación para aguas residuales débiles y medias de origen urbano entre 0,4 y 0,44 (Metcalf y Eddy, 1995) siendo el agua muy biodegradable para valores mayores a 0,4. Otros autores citan valores entre 0,5 y 0,63 para esta relación.

Uno de los parámetros más críticos en el proceso de nitrificación y desnitrificación es la relación DQO/N debido a que el contenido carbono-nitrógeno del AR determina la competencia en el crecimiento que se establece las poblaciones de microorganismos autótrofos y heterótrofos. Tradicionalmente se ha considerado que la influencia de esta relación es mayor en un proceso convencional de lodos activos que en un proceso de eliminación biológica de nitrógeno. Sin embargo algunos estudios demuestran que la influencia de relación $\mathrm{DQO} / \mathrm{N}$ sobre el proceso de nitrificación es similar en ambos sistemas. Esta relación es especialmente importante en el diseño y modelado de los procesos de nitrificación y desnitrificación.

Tradicionalmente la relación $\mathrm{DBO}_{5} / \mathrm{N}$ está estrechamente relacionada con el potencial de nitrificación con valores que se encuentran en un intervalo de 4,73 a 6, sin embargo Henze cita valores para aguas residuales para la relación $\mathrm{DBO} / \mathrm{N}$ entre 3,0 y 4,0 para aguas con concentraciones bajas, 4 y 6 típicas y de 6 a 8 altas, así mismo (Orhon et al., 1997) proponen, que para valores menores a 4 la nitrificación debe considerarse como un proceso separado.

Otra relación importante es la DQO/N relacionada estrechamente con los procesos de desnitrificación con valores que se encuentran entre 6 y $8 \mathrm{mg} \mathrm{DQO} / \mathrm{mg} \mathrm{N}$ para aguas con concentración de nitrógeno bajas, de 8 a12 típicas y de 12 a 16 altas. A rasgos generales, valores superiores a 9 para esta relación suponen buenas eficacias en el proceso de desnitrificación. En cambio, el proceso se ve afectado para valores inferiores a 5.

En el caso del fósforo al igual que el nitrógeno actúa como nutriente permitiendo así el desarrollo de los procesos biológicos siendo necesario mantener valores de fósforo en el agua influente que permitan el crecimiento de los microorganismos. Numerosos estudios han reportado valores para la relación P/DQO en el agua de entrada entre 0,05 y 0,1 (Mino et al., 1998) y para la relación $\mathrm{P}_{2} \mathrm{DBO}_{5}$ entre 0,037 y 0,044 (Metcalf y Eddy, 1995), valores similares son propuestos por Ekama y Marais (1986) en un intervalo de 0,03 a 0,05 para esta relación.

Asimismo se ha observado la influencia que tiene esta relación sobre el proceso de eliminación biológica de fósforo encontrando que para valores menores de $0,02 \mathrm{mgP} / \mathrm{mg}$ DQO en el agua de entrada tiende a favorecer el crecimiento de las bacterias acumuladoras de glicógeno (GAO) que compiten por el sustrato con las PAO, por lo que su presencia también afectaría al proceso de eliminación biológica de fósforo (Mino et al., 1998). De este modo, la relación $\mathrm{P} / \mathrm{DQO}$ en el influente de un proceso de eliminación biológica de fósforo marcará el grado de eficacia de dicho proceso.

La relación SSV/SST es utilizada como un indicador del grado de tratamiento necesario para un AR debido a la relación que existe entre los SSV y el contenido de materia orgánica. Valores encontrados para esta relación son reportados en la bibliografía con valores de 0,6.

Como ya se ha comentado en el presente trabajo, la capacidad de una planta para el tratamiento de aguas residuales se diseña tradicionalmente mediante la determinación de la DQO y $\mathrm{DBO}_{5}$ así como los contenidos de nutrientes $\mathrm{N}$ y $\mathrm{P}$ en el influente. Sin embargo este conjunto de datos experimentales no permite estimar con precisión el potencial de un tratamiento biológico ya que considera el valor total de la DBO y DQO sin tener en cuenta que solo parte de este sustrato es utilizado por los microorganismos. Los estudios realizados en esta área 
han logrado avances notables en el fraccionamiento de la materia orgánica y la identificación de los componentes de fácil utilización por los microorganismos.

Los distintos modelos propuestos para el tratamiento de aguas residuales han requerido la caracterización detallada del AR siendo el principal objetivo la identificación de las fracciones orgánicas con distintas tasas de biodegrabiliad. La caracterización detallada del AR con todas sus fracciones en muchos casos es un trabajo extenso y dispendioso, siendo necesario utilizar datos bibliográficos o empíricos para la obtención de los componentes del AR según los modelos para aguas residuales. Existen dos formas de obtener estos valores, la primera utilizando las ecuaciones descritas para el fraccionamiento de la DQO, N, P y SST (ecuaciones 1-9) o mediante las relaciones tipo I.

Otra forma de calcular estos componentes es mediante la utilización de las relaciones tipo II (Tabla 10), propuestas en este estudio para el fraccionamiento de la DQO y la DBO $\mathrm{LIM}_{\text {. }}$

Tabla 10. Resultados obtenidos para las relaciones propuestas tipo II.

\begin{tabular}{|c|c|c|}
\hline TIPO II & MEDIA & SD \\
\hline SS:DQO & 0,37 & 0,17 \\
\hline $\mathrm{S}_{\mathrm{F}}: \mathrm{DQO}_{\mathrm{SOL}}$ & 0,61 & 0,22 \\
\hline$S_{1}: D Q O$ & 0,08 & 0,05 \\
\hline $\mathrm{X}_{\mathrm{s}}: \mathrm{DQO}$ & 0,37 & 0,14 \\
\hline $\mathrm{x}_{1}: \mathrm{DQO}$ & 0,15 & 0,09 \\
\hline Sa:DQO & 0,12 & 0,07 \\
\hline$S_{F}: D Q O$ & 0,28 & 0,17 \\
\hline $\mathrm{S}_{\mathrm{s}}: \mathrm{DBO}_{\text {LIM }}$ & 0,49 & 0,19 \\
\hline $\mathrm{X}_{\mathrm{s}}: \mathrm{DBO}_{\mathrm{LIM}}$ & 0,51 & 0,19 \\
\hline $\mathrm{S}_{\mathrm{I}}: \mathrm{DQO}_{\mathrm{SOL}}$ & 0,14 & 0,08 \\
\hline Sa:DQO ${ }_{\text {SOL }}$ & 0,29 & 0,15 \\
\hline SS:DQOsol & 0,85 & 0,1 \\
\hline
\end{tabular}

Las diferentes fracciones en las que se componen la DQO y DBO condicionan los procesos de depuración biológica y en particular la eliminación biológica de nutrientes. Así, la fracción fácilmente biodegradable $\left(\mathrm{S}_{\mathrm{S}}\right)$ es utilizada como fuente de carbono en la desnitrificación, los ácidos grasos volátiles (AGV) son de vital importancia en las etapas anaeróbicas en los procesos de eliminación biológica de fósforo; la fracción lentamente biodegradable $S_{\mathrm{F}}$ se hidroliza y fermenta para producir fracciones solubles entre ellas ácidos grasos volátiles $\left(\mathrm{S}_{\mathrm{A}}\right)$, todo esto muestra la importancia que tiene el correcto fraccionamiento del AR. La fracción de sustrato fácilmente biodegradable $\left(\mathrm{S}_{\mathrm{S}}\right)$ son compuestos de pequeño peso molecular que pueden ser absorbidos directamente por los microorganismos para ser metabolizados posteriormente. Se componen en general de hidratos de carbono monomérico, ácidos grasos volátiles, aminoácidos y alcoholes, pueden representar el 30\% de la DQO según los siguientes autores Henze et al., 1987; 32\%: Orhon et al., 2002; 30\%; IWA (Henze et al., 2000); $30 \%$, siendo el valor medio encontrado en este estudio para esta fracción ( $\left.S_{S} / D Q O\right)$ del $37 \%$ con una desviación estándar del 17\% encontrándose así dentro de los intervalos propuestos en la bibliografía.

La fracción fácilmente biodegradable compuesta por ácidos grasos volátiles $\left(\mathrm{S}_{\mathrm{A}}\right)$ representa alrededor del 10 $\%$ de la DQO según la IWA (Henze et al.,2000): 2-10\%; Henze et al., 1992: 8-10\%). Asimismo la fracción fácilmente biodegradable fermentable $\left(\mathrm{S}_{\mathrm{F}}\right)$ representa el 20\% de la DQO IWA (Henze et al.,2000): 10-20\%; Henze et al., 1992: 5-22\%). Los valores medios encontrados para la relación $\mathrm{S}_{\mathrm{A}} / \mathrm{DQO}$ y $\mathrm{S}_{\mathrm{F}} / \mathrm{DQO}$ estudiados en el presente trabajo son del $12 \%$ y $28 \%$ respectivamente.

La materia orgánica lentamente biodegradable particulada definida en el modelo como $\mathrm{X}_{\mathrm{S}}$ cubre un amplio rango de tamaños desde solubles hasta coloidales y de partículas orgánicas de estructura compleja. Por lo tanto cabe esperar que la hidrólisis sea el proceso limitante de la velocidad de utilización de este componente, una característica común de esta fracción es que no puede atravesar la pared celular ya que necesita sufrir una hidrólisis antes de su absorción (Orhon y Artan, 1994). Esta fracción representa entre el 40 al 60\% de la DQO, 
algunos autores citan diversos valores como los presentados por la IWA (Henze et al.,2000) entre el 30 y $60 \%$, Ekama y Marais, 1986 de 62\%, Henze et al., 1987 con 43\%, Orhon et al., 2002 del 62\%. Sin embargo, la fracción Xs/DQO en este estudio presento un valor del $37 \%$ encontrándose por debajo de los propuestos en la bibliografía.

La fracción inerte ha sido dividida en dos fracciones, no biodegradable soluble $\left(\mathrm{S}_{\mathrm{I}}\right)$ y no biodegradable particulada $\left(\mathrm{X}_{\mathrm{I}}\right)$, la fracción soluble SI entra y sale del sistema sin participar en ningún proceso bioquímico mientras que la fracción particulada $X_{I}$ queda atrapada y acumulada en los fangos saliendo del sistema a través de la purga (Orhon y Artan, 1994). Estas fracciones representan el 10\% de la DQO para la S I el 15\% para la

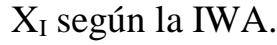

\section{Conclusiones}

Los datos recopilados recibieron un tratamiento estadístico obteniendo una serie de valores para las relaciones propuestas entre los distintos datos experimentales y componentes, que caracterizan las aguas residuales. Con los resultados obtenidos es posible caracterizar un AR a partir de pocos datos, tales como la DQO, DBO, N y P.

Se evaluaron 22 depuradoras distribuidas en la Comunidad Valenciana y Murcia que son representativas de ARU sin apreciable impacto por vertidos industriales excepto en algunas EDAR donde se observa un fuerte carácter industrial.

Los resultados obtenidos son de gran importancia ya que en muchos casos las relaciones entre datos experimentales condicionan los procesos biológicos en particular los referentes a la eliminación biológica de nutrientes.

En general, se ha observado una afinidad entre los valores obtenidos en el presente trabajo y los encontrados en bibliografía. Existen casos con pequeñas discrepancias que han sido justificados en base a la composición inicial del ARU en el momento de la caracterización, esto es, casos en que el ARU presentaba deficiencia de nutrientes o presencia de vertidos industriales.

Se obtuvieron 27 relaciones clasificadas en dos categorías (tipo I y tipo II) que permiten la caracterización del ARU influente a una depuradora a partir de datos experimentales de análisis rutinario como la $\mathrm{DQO}, \mathrm{DBO}_{5}$, SST, SSV, N y P.

\section{Agradecimientos}

Se agradece la colaboración al grupo de investigación Calagua de la Universitat Politècnica de València y la Universitat de València.

\section{Referencias bibliográficas}

APHA, American Public Health Association, American Water Works Association and Water Environmental Federation, (2005) Standard Methods for the Examination of Water and Wastewater. 20th Ed., Washington D. C. https://doi.org/10.12999/awwa.c651.05

Ekama ,G.A.; Dold, P.; Marais, G.v.R. (1986) Procedures for determining influent COD fractions and the maximum specific growth rate of heterotrophs in activated sludge systems. Water. Sci. Technol. Vol .18, №, 91-114.

Ekama, G.A.; Marais, G.v.R. (1979) Dynamic Behaviour of the Activated Sludge Process. J. Water Pollution Control Fed., Vol.51, 534-556.

Henze, M.; Grady, C. P. L.; Gujer, W.; Marais, G. v. R.; Matsuo, T. (1987) Activated Sludge Model No.1. IAWPRC. Scientific and Technical Report No.1. IAWPRC, London. ISSN 1010-707X. https://doi.org/10.1016/0043-1354(87)90058-3 
Henze, M., Gujer, W., Mino, T. and van Loosdrecht, M. C. M. (2000) Activated Sludge Models ASM1, ASM2, ASM2d and ASM3. Scientific and Technical Report No. 9. IWA Publishing, London. https://doi.org/10.2166/9781780402369

Janssen, P.M (1994).Operating experiences on two full escale plants, retrofitted for biological phosphorus removal. Nutrient removal from wastewaters. Technomic Publishing co.inc. Pennsylvania.

Mujeriego, R.(1990) Manual Práctico de Riego con Agua Residual Municipal Regenerada. Universidad Politécnica de Cataluña, Barcelona.

Metcalf y Eddy. (1995) Ingeniería de Aguas residuales. Tratamiento, vertido y reutilización. 3 $3^{\text {a }}$ Edición. Editorial McGraw-Hill, Madrid.

Mino, T., Van Loosdrecht, M. C. M., \& Heijnen, J. J. (1998). Microbiology and biochemistry of the enhanced biological phosphate removal process. Water research, 32(11), 3193-3207. https://doi.org/10.1016/s00431354(98)00129-8

Moosbrugger, R. E.; Wentzel, M. C.; Ekama, G. A.; Marais, G. v. R. (1992) Simple titration procedures to determine $\mathrm{H}_{2} \mathrm{CO}^{*}$ alkalinity and short-chain fatty acids in aqueous solutions containing known concentrations of ammonium, phosphate and sulphide weak acid/bases. Water Research Commission, Report No. TT 57/92. University of Cape Town, Research Report W 74, Pretoria, Republic of South Africa.

Orhon, D.; Sözen, S.; Artan, N. (1996) The effect of heterotrophic yield on the assessment of the correction factor for anoxic growth. Water Science and Technology. Vol. 34, No. 5-6, 67-74. https://doi.org/10.1016/0273-1223(96)00630-0

Sözen, S.; Ubay Çokgör, D.; Orhon, D.; Henze, M. (1998) Respirometric analysis of activated sludge behaviour-II. Heterotrophic growth under aerobic and anoxic conditions. Water Science and Technology. Vol. 32, No. 2, 476-488. https://doi.org/10.1016/s0043-1354(97)00210-8

Seco, A.; Ribes, J.; Ferrer, J.; Serralta, J.; Manga, J. (2004) Biological Nutrient Removal Model No. 1 (BNRM1). Water Science and Technology.Vol. 50(6), 69-78. 